Article

\title{
Contributing Factors in Adolescents' Mental Well-Being-The Role of Socioeconomic Status, Social Support, and Health Behavior
}

\author{
Gabriella Nagy-Pénzes ${ }^{1,2}$, Ferenc Vincze ${ }^{2}$ (1) and Éva Bíró ${ }^{2, *}$ (1) \\ 1 Doctoral School of Health Sciences, University of Debrecen, 26. Kassai Street, 4028 Debrecen, Hungary; \\ penzes.gabriella@med.unideb.hu \\ 2 Department of Public Health and Epidemiology, Faculty of Medicine, University of Debrecen, \\ 26. Kassai Street, 4028 Debrecen, Hungary; vincze.ferenc@med.unideb.hu \\ * Correspondence: biro.eva@med.unideb.hu; Tel.: +36-52-512-765 (ext. 77405)
}

Received: 16 September 2020; Accepted: 16 November 2020; Published: 18 November 2020

\begin{abstract}
Mental disorders are common in adolescents, and for effective interventions we should be aware of their determinants. However, there are only a small number of studies investigating the combined effect of multiple factors. Therefore, our aim is to assess the impact of socioeconomic status, social support, and health behavior on adolescents' mental well-being. A cross-sectional health survey of 1641 children was carried out in accordance with the study protocol of the Hungarian Health Behavior in School-aged Children survey. Multivariate multiple regression was used to analyze the main determinants of mental well-being. The boys' mental well-being was favorable compared to girls; lower subjective family wealth was associated with lower life satisfaction and depressive mood. Life satisfaction was positively related to healthy eating, social support, and physical activity. Unhealthy eating, sedentary lifestyle, and lower social support were associated with higher depression scores. Higher social support reduces psychosomatic symptoms, while unhealthy eating and spending a lot of time in front of the computer increase them. Both social support and healthy lifestyle seem to be protective against mental health problems among adolescents, and thus interventions should focus on these factors regardless of the socioeconomic status of the participants, with special attention given to girls.
\end{abstract}

Keywords: adolescents; mental well-being; socioeconomic status; social support; health behavior

\section{Introduction}

Adolescence, the transition from childhood to adulthood, is a crucial period of life. However, the physical, emotional, intellectual, and social changes at this time can increase the risk of mental health problems. Mental and behavioral disorders are frequent among youth, and one fifth of adolescents experience some kind of mental health problem [1]. Almost half of all adult mental disorders begin in the teenage years [2], and the poor mental health of young people is associated with lower educational achievement, substance abuse, suicide, violence, and sexual health problems [3]. More than one tenth of adolescents in the World Health Organization (WHO) European Region have some kind of mental health problem, and this is the leading cause of disability in young people. Depression is the most common condition in children and adolescents, and suicide is one of the leading causes of death in youth [4]. Based on the results of the Global Burden of Disease Study 2010, the highest proportion of disability-adjusted life years (DALYs) for mental disorders occurred in the 10-29 age group, and the burden of depressive disorders (responsible for more than 7000 DALYs in thousands) exceeds the burden from alcohol and drug use [5]. 
One of the main information sources regarding young people's well-being, behavior, and social context is the Health Behavior in School-aged Children (HBSC) Survey, which has run for nearly 40 years. It is conducted every four years in 50 countries and regions across Europe and North America as a cross-national study [6]. According to the HBSC 2013/14 survey ascertainments, children's life satisfaction declines between the ages of 11 and 15. Fifteen-year-old girls have reported lower life satisfaction and more multiple health complaints than boys [7]. In Hungary, there was no significant change in life satisfaction between grades, but regarding gender differences it can be stated that, in higher grades, the life satisfaction of boys was favorable and they also reported fewer health complaints. In the case of depression, girls scored significantly higher than boys [8].

Therefore, promoting the well-being and healthy lifestyle of adolescents can have far-reaching effects on their present and future mental health [9]. However, for effective interventions, we need reliable data regarding the risk and protective factors that determine the epidemiological properties of mental disorders. These include-among other factors-genetic susceptibility, socioeconomic and demographic factors, lifestyle, somatic diseases, and family and environmental factors $[3,10]$. Several studies have proved that lower socioeconomic status is associated with unfavorable mental health among adolescents [11-13]. Mental problems are deep-rooted in the social and emotional environment of the person. Safe and supportive families, together with positive and supportive peers, are essential in supporting youth to achieve their best health [14]. Family can be protective in many ways; one of these is parental communication, which promotes prosocial values that help youths cope with stressful situations [15]. Those who are able to communicate easily with their parents are more likely to have higher life satisfaction and fewer health complaints. Higher support from friends can help protect against depression and isolation, and interactions with friends strengthen the ability to deal with stress. Students with higher perceived classmate support have reported fewer subjective health complaints and higher life satisfaction [15,16]. Mental well-being is also influenced by behavior [17]; it is proven that physical activity and raw fruit and vegetable consumption have a positive effect on mental health, as well as reducing anxiety symptoms and depression. However, a low level of physical activity and sedentary behavior are significantly associated with mental health problems [18-20]. All in all, we can assume that there are complex interactions between social and economic factors, behavior, and mental health in adolescence; however, there are relatively few comprehensive studies investigating the combined effect of these. If we search for information related to adolescents in the PubMed database with the search terms "mental health" AND "socioeconomic status" AND "health behavior", we will find only 40 items (filter activated: adolescent: 13-18 years; date of search: 09 July 2020). After checking the titles, it appears that some of the search results are not relevant, and very few focus on the effect of health behavior (i.e., healthy diet and physical activity). Therefore, to fill this gap the aim of our study is to assess the combined impact of sex, socioeconomic status, social support, and health behavior on adolescents' mental health. Then, we evaluated the sex differences across the studied mental well-being variables (Is sex related to all the examined mental well-being indicators? If yes, are there any sex differences across the mental well-being indicators?). The reason for this comprehensive analysis is that this will bring us closer to the real-life situation compared to investigating the associations on a pairwise basis.

\section{Materials and Methods}

\subsection{Study Population}

A cross-sectional health survey of a school-aged child population was carried out in the second largest Hungarian town (Debrecen) in accordance with the study protocol of the Hungarian HBSC survey [8]. The study population consisted of 5th, 7th, 9th, and 11th grade students who were enrolled in different schools of the town. Multistage, stratified cluster sampling was performed where the strata included the school maintainer (municipality and church), school type (primary and secondary school), 
and grade (the details were published elsewhere: [21]). Finally, the sample consisted of 2208 students from 86 classes of 10 schools. All the students from the selected grades were included in the sample.

\subsection{Data Collection}

Data collection was carried out during November 2015 with a self-reported, anonymous online questionnaire, which was identical to the questionnaire of the Hungarian Health Behavior in School-aged Children (HBSC) survey [8]. The research was performed with ethical approval; written parental consent was obtained from all participants, but, independent of the given parental consent, the participation of the students was voluntary.

In accordance with the Hungarian HBSC survey [8], three questionnaires were used: a full-length one for 15- and 17-year-olds, a shorter one for 13-year-olds, and the shortest version for 11-year-olds. Only the common domains of the questionnaires analyzed in the present manuscript will be described below. During the evaluation of these scales, national and international protocols were followed $[8,22]$.

This study used 33 questions divided into four main sections: socioeconomic and demographic data, social support, health behavior, and mental well-being.

\subsubsection{Socioeconomic and Demographic Data}

The following socioeconomic and demographic data were collected: gender, age, place of residence (Debrecen or other surrounding settlements), type of school (primary school, vocational school, vocational high school, and high school), parental educational attainment (university or college, secondary school, vocational certificate, maximum primary school, do not know), subjective perception of family wealth (5-item scale with answers from "very well off" to "not at all well off"; these were collapsed into three categories: not well-off/average/well-off), and family affluence. The last was measured by the Family Affluence Scale (FAS), for which the total score (0-13 points) was calculated based on car, computer, and dishwasher ownership; having a bathroom and one's own bedroom; and the number of family holidays abroad during the last year. Then, three categories were created based on the total points: $0-5$ low, 6-7 medium, 8-13 high affluence [8,22].

\subsubsection{Social Support}

To measure perceived social support from family and friends (peer support), we used the Multidimensional Scale of Perceived Social Support (MSPSS). There were eight items by which to determine the level of family and peer support on a 7-point Likert scale. The students were asked to mark how much they agree (from 1, "very strongly disagree", to 7, "very strongly agree") with the statements about their family and friends. The family support items were the following statements: "my family really tries to help me", "I get emotional help and support I need from my family", "I can talk about problems with my family", and "my family is willing to help me make decisions". The peer support contained the next items: "my friends really try to help me", "I can count on my friends when things go wrong", "I have friends with whom I can share my joys and sorrows", and "I can talk about my problems with my friends". The Cronbach's alpha was 0.89 for the family support scale and 0.92 for the peer support scale. Finally, the summary of the scores was calculated separately for the two parts (total score ranged from 4 to 28), where a higher score means higher support. Besides social support, the quality of family communication was also measured with the short version of the clear communication scale from the Family Dynamics Measure II (FDMII). In this part of the questionnaire, there were four statements, and the students were asked to mark on a five-point scale how much they agree ( 1 , "strongly agree"; 5 , "strongly disagree") with the following: "in the family, the important things are talked about", "when she/he speaks, someone listens to what she/he says", "they ask questions when they don't understand each other", "when there is a misunderstanding, they talk it over until it's clear". The Cronbach's alpha for the clear communication scale was 0.84 . The summary of the reversed scores was calculated (total score ranged from 4 to 20), where a higher score means better communication [8,22]. 


\subsubsection{Health Behavior}

Health behavior was assessed in terms of eating habits and physical activity. Dietary habits, such as the regularity of having breakfast (on how many days during the week), were measured. The frequency of consumption of healthy (fruits, vegetables) and unhealthy food (sweets, sugar-containing soft drinks, energy drinks, salty snacks, and fast foods) was assessed with a seven-item scale from "never" to "more than once a day". Questions about the frequency of having breakfast and the evening meal together with parents were also included. There were also questions regarding active (regularity of moderate-to-vigorous and vigorous physical activity) and passive ways of spending free time. Sedentary behavior was measured with the time spent on three types of screen-based activity a day. Students were asked how many hours a day of their free time they usually spend watching TV, videos, and DVDs; playing games on a computer; or using electronic devices not for playing (e.g., Internet use, chat, e-mailing). Response options referred to a nine-point Likert scale from none at all to seven hours or more $[8,22]$.

\subsubsection{Mental Well-Being}

The mental well-being of the students was characterized by life satisfaction, measured by the Cantril ladder, where a score of 0 represents the worst possible life and ten represents the best possible life; depression; and the frequency of psychosomatic symptoms. To measure depression, the short version of the Child Depression Inventory (CDI) was used. It contains statements about eight different symptoms of depression and the summarized score ranges from 0 to 16 . A higher value means a higher risk of depression, and based on the scores, three categories can be formed: normal mood ( $0-1$ point), disturbed mood ( $2-3$ points), and depressive mood ( 4 or above) $[8,23]$. The health complaints index was used for the assessment of the frequency of psychosomatic symptoms (e.g., headache, feeling low/nervous, difficulties in getting to sleep). The index is calculating by summing up the scores of each item; values range from 9 to 45 , and higher values indicate more health complaints $[8,22]$. The Cronbach's alpha was 0.78 for the depression scale and 0.87 for the health complaints index.

\subsection{Data Analysis}

The data analysis was conducted in several steps. First of all, variables that were not completely filled in were imputed to overcome the constraint of biased or overestimated results that may arise from missing data. Missing values were classified as random, and multiple imputation by fully conditional specification, which is an iterative Markov Chain Monte Carlo (MCMC) method, was used to impute all missing data in the studied database.

Next, the health behavior and social support questions were evaluated with factor analysis in order to generate health behavior and social support patterns. The number of factors with eigenvalues higher than one was determined using principal component analysis and varimax (orthogonal) rotation. The scree plot curve had declinations at seven factors, which also indicated a seven-factor model, similar to the eigenvalue specification. Health behavior questions with factor loadings $>0.50$ were used to interpret each pattern. The model significance was tested with Bartlett's test of sphericity $(p<0.001)$ and the goodness of fit was tested with the Kaiser-Meyer-Olkin Measure of Sampling Adequacy $(\mathrm{KMO}=0.716)$, which convinced us that the seven-factor model depicted the latent structure of the original set of questions. The resulting standardized factor scores were introduced into the multivariate models as continuous explanatory variables.

Then, we used descriptive statistics to provide an overview of the respondents' characteristics, and finally multivariate multiple regression was used to analyze the main determinants of mental well-being. The method differs from ordinary multiple regression because several outcome variables (in this case, life satisfaction, depression, psychosomatic symptoms) are jointly regressed on a set of predictors (here, socioeconomic and demographic data, social support, health behavior). To estimate 
the overall statistical significance of the models, we calculated Wilks' lambda based on a multivariate analysis of variance (MANOVA) procedure, followed by multivariate multiple regressions. Based on the analyses, firstly we determined the R-squares for each outcome measure. Secondly, we studied the relationship between the adolescents' mental well-being and studied covariates in one model together. Associations were quantified by regression coefficients $(\beta)$ and the corresponding $95 \%$ confidence interval (CI). Post-estimation with hypothesis testing was used to analyze the gender differences across the studied outcomes. To avoid the inflated likelihood of a Type I error due to multiple testing, the significance level of each test was adjusted using Bonferroni correction, which divides the significance level by the number of tests. $p$-values less than 0.008 were considered to be significant $(0.05 / 6=0.008)$. Statistical computation was performed with Intercooled Stata 12.0 for Windows [24].

\section{Results}

In the present manuscript, data from the 5 th grade $(n=253)$ were excluded from the data analysis because depression was not assessed in that age group. Of the remaining 1955 students, 1641 filled out the questionnaire, so the overall response rate was $83.9 \%$. The adolescents' characteristics are summarized in Table 1. The average age was 15.28 years (standard deviation, SD: 1.70), and the proportion of boys was $60.8 \%$. Approximately $62 \%$ of the respondents lived in Debrecen, and $42 \%$ of the adolescents studied in high school. Almost one third of the fathers and nearly $40 \%$ of the mothers had university or college certificates. Twelve percent of the respondents had a high FAS score, but on the other hand nearly $40 \%$ of the adolescents described their family wealth status as well-off. The average score of life satisfaction was 7.42 (SD: 1.94), and the score was 21.17 (SD: 7.77) for psychosomatic symptoms. The mean score of the depression scale was 2.12 (SD: 2.44 ), and $21.8 \%$ of the students belonged to the depressive mood category. The percentages of missing values for the study ranged between $0.24 \%$ (residence) and $13.16 \%$ (depression scale). Detailed information regarding the socioeconomic and demographic data after multiple imputation can be found in Table A1 (in Appendix A).

Table 1. Characteristics of the respondents before the multiple imputation of missing values.

\begin{tabular}{|c|c|c|c|}
\hline & & $\mathbf{N}(\%)$ & Mean $( \pm$ SD) \\
\hline \multicolumn{2}{|c|}{ Age } & & $15.28(1.70)$ \\
\hline \multirow{2}{*}{ Gender of students } & Male & $997(60.76 \%)$ & \\
\hline & Female & $644(39.24 \%)$ & \\
\hline \multirow{5}{*}{ Educational attainment of father } & Not known & $181(11.62 \%)$ & \\
\hline & Primary school or less & $60(3.85 \%)$ & \\
\hline & Vocational school & $434(27.87 \%)$ & \\
\hline & Secondary school/high school & $375(24.08 \%)$ & \\
\hline & University/college & $507(32.56 \%)$ & \\
\hline \multirow{5}{*}{ Educational attainment of mother } & Not known & $131(8.47 \%)$ & \\
\hline & Primary school or less & $60(3.88 \%)$ & \\
\hline & Vocational school & $214(13.84 \%)$ & \\
\hline & Secondary school/high school & $515(33.31 \%)$ & \\
\hline & University/college & $626(40.49 \%)$ & \\
\hline \multirow{3}{*}{ Family affluence } & Low & $645(43.58 \%)$ & \\
\hline & Medium & $656(44.32 \%)$ & \\
\hline & High & $179(12.09 \%)$ & \\
\hline
\end{tabular}


Table 1. Cont.

\begin{tabular}{|c|c|c|c|}
\hline & & $\mathbf{N}(\%)$ & Mean $( \pm \mathrm{SD})$ \\
\hline \multirow{3}{*}{ Subjective perception of family wealth } & Not well-off & $63(3.91 \%)$ & \\
\hline & Average & $918(56.95 \%)$ & \\
\hline & Well-off & $631(39.14 \%)$ & \\
\hline \multirow{2}{*}{ Residence } & Debrecen & $1012(61.82 \%)$ & \\
\hline & Other surrounding settlements & $625(38.18 \%)$ & \\
\hline \multirow{4}{*}{ Type of school } & Primary school & $358(21.95 \%)$ & \\
\hline & Vocational school & $62(3.80 \%)$ & \\
\hline & Secondary school & $516(31.64 \%)$ & \\
\hline & High school & $695(42.61 \%)$ & \\
\hline \multicolumn{2}{|c|}{ Life satisfaction } & & $7.42(1.94)$ \\
\hline \multicolumn{2}{|c|}{ Depression scale } & & $2.12(2.44)$ \\
\hline \multicolumn{2}{|c|}{ Psychosomatic symptoms } & & $21.17(7.77)$ \\
\hline
\end{tabular}

$\mathrm{N}$ : number of cases; SD: standard deviation.

\subsection{Result of the Factor Analysis}

The seven factors were responsible for $66.12 \%$ of the total variance (Table A2). Factor 1 was determined by different types of unhealthy foods (sweets, sugar-containing soft drinks, salty snacks, fast-foods, and energy drinks), and factor 2 was related to the questions on entertainment screen time (computer games and television or video watching). The questions about physical activity formed factor 3 (frequency of vigorous physical activity, weekly hours of vigorous physical activity and moderate-to-vigorous physical activity), while the different questions about social support connected to factor 4 (perceived social support from family, quality of family communication, perceived social support from friends (peer support)). Factor 5 consisted of using electronic devices not for playing. The following questions make up the 6th factor: eating together with parents and breakfast consumption. Factor 7 comprised of questions on healthy food consumption (vegetables and fruits).

After evaluating the contents of factor-building statements, factor 1 to factor 7 were referred to as "unhealthy food consumption", "entertainment screen time", "physical activity", "social support", "using the computer not for playing", "breakfast consumption and family meals", and "healthy food consumption", respectively.

\subsection{Determinants of Mental Well-Being}

In the multivariable multiple regression analysis (Table 2), Wilks' lambda showed that the model is statistically significant $(p<0.001)$. A full model including all 15 independent variables explained 19\%, $24 \%$, and $17 \%$ of the variance in the outcome variables life satisfaction, depression, and psychosomatic symptoms, respectively. 
Table 2. Multivariate multiple regression analysis of socioeconomic and demographic data and social support, health behavior, and mental well-being indicators among adolescents.

\begin{tabular}{|c|c|c|c|c|}
\hline & & $\begin{array}{c}\text { Life Satisfaction } \\
\quad \beta(95 \% \mathrm{CI})\end{array}$ & $\begin{array}{c}\text { Depression } \\
\beta(95 \% \mathrm{CI}) \\
\end{array}$ & $\begin{array}{c}\text { Psychosomatic Symptoms } \\
\beta(95 \% \text { CI })\end{array}$ \\
\hline Gender of students & Male (ref: female) & $0.42(0.21 ; 0.62) *$ & $-0.90(-1.14 ;-0.67) *$ & $-3.05(-3.88 ;-2.21) *$ \\
\hline \multirow{4}{*}{ Educational attainment of father } & Not known (ref: university/college) & $0.34(-0.02 ; 0.70)$ & $0.31(-0.11 ; 0.73)$ & $1.83(0.33 ; 3.32) *$ \\
\hline & Primary school (ref: university/college) & $-0.39(-0.85 ; 0.07)$ & $0.23(-0.30 ; 0.77)$ & $0.79(-1.13 ; 2.70)$ \\
\hline & Vocational school (ref: university/college) & $-0.18(-0.42 ; 0.07)$ & $-0.02(-0.30 ; 0.27)$ & $1.04(0.03 ; 2.05)^{*}$ \\
\hline & Secondary school/high school (ref: university/college) & $-0.03(-0.27 ; 0.22)$ & $-0.06(-0.34 ; 0.23)$ & $-0.26(-1.27 ; 0.75)$ \\
\hline \multirow{4}{*}{ Educational attainment of mother } & Not known (ref: university/college) & $-0.72(-1.12 ;-0.32) *$ & $-0.37(-0.84 ; 0.10)$ & $-1.53(-3.20 ; 0.14)$ \\
\hline & Primary school (ref: university/college) & $0.26(-0.20 ; 0.72)$ & $-0.22(-0.75 ; 0.31)$ & $-2.15(-4.05 ;-0.25)^{*}$ \\
\hline & Vocational school (ref: university/college) & $-0.05(-0.33 ; 0.22)$ & $0.05(-0.27 ; 0.37)$ & $-1.20(-2.35 ;-0.06)^{*}$ \\
\hline & Secondary school/high school (ref: university/college) & $0.07(-0.14 ; 0.28)$ & $-0.18(-0.43 ; 0.06)$ & $-0.09(-0.96 ; 0.79)$ \\
\hline \multirow{2}{*}{ Subjective perception of family wealth } & Not well-off (ref: well-off) & $-1.25(-1.70 ;-0.80) *$ & $0.80(0.27 ; 1.32) *$ & $1.54(-0.33 ; 3.41)$ \\
\hline & Average (ref: well-off) & $-0.48(-0.66 ;-0.29) *$ & $-0.04(-0.25 ; 0.17)$ & $0.09(-0.66 ; 0.84)$ \\
\hline \multirow{2}{*}{ Family affluence } & Low (ref: high) & $-0.22(-0.51 ; 0.08)$ & $-0.02(-0.37 ; 0.32)$ & $-0.20(-1.43 ; 1.03)$ \\
\hline & Medium (ref: high) & $-0.10(-0.37 ; 0.17)$ & $0.05(-0.26 ; 0.37)$ & $-0.19(-1.31 ; 0.94)$ \\
\hline \multirow{3}{*}{ Type of school } & Primary school (ref: high school) & $0.29(-0.02 ; 0.60)$ & $0.02(-0.34 ; 0.38)$ & $-1.49(-2.77 ;-0.21)^{*}$ \\
\hline & Vocational school (ref: high school) & $-0.34(-0.79 ; 0.12)$ & $-0.06(-0.59 ; 0.46)$ & $-0.24(-2.11 ; 1.64)$ \\
\hline & Secondary school (ref: high school) & $-0.18(-0.39 ; 0.03)$ & $-0.02(-0.27 ; 0.22)$ & $-0.37(-1.25 ; 0.51)$ \\
\hline
\end{tabular}


Table 2. Cont.

\begin{tabular}{|c|c|c|c|c|}
\hline & & $\begin{array}{c}\text { Life Satisfaction } \\
\beta(95 \% \text { CI })\end{array}$ & $\begin{array}{c}\text { Depression } \\
\beta(95 \% \mathrm{CI})\end{array}$ & $\begin{array}{c}\text { Psychosomatic Symptoms } \\
\beta(95 \% \text { CI })\end{array}$ \\
\hline Residence & Debrecen (ref: other surrounding settlements) & $-0.18(-0.36 ; 0.00)$ & $0.03(-0.18 ; 0.25)$ & $0.64(-0.11 ; 1.39)$ \\
\hline \multirow{8}{*}{ Factors } & Social support & $0.42(0.34 ; 0.50) *$ & $-0.75(-0.84 ;-0.65) *$ & $-1.13(-1.47 ;-0.79) *$ \\
\hline & Breakfast consumption and family meals & $0.19(0.11 ; 0.28)^{*}$ & $-0.46(-0.56 ;-0.36) *$ & $-1.52(-1.88 ;-1.17)^{*}$ \\
\hline & Healthy food consumption & $0.20(0.11 ; 0.28) *$ & $-0.08(-0.18 ; 0.01)$ & $0.16(-0.18 ; 0.50)$ \\
\hline & Unhealthy food consumption & $0.04(-0.05 ; 0.12)$ & $0.15(0.05 ; 0.24)^{*}$ & $0.84(0.50 ; 1.19)^{*}$ \\
\hline & Physical activity & $0.19(0.10 ; 0.27) *$ & $-0.20(-0.30 ;-0.10) *$ & $-0.18(-0.53 ; 0.17)$ \\
\hline & Entertainment screen time & $-0.15(-0.24 ;-0.06) *$ & $0.17(0.07 ; 0.27)^{*}$ & $0.10(-0.26 ; 0.46)$ \\
\hline & Using the computer not for playing & $0.02(-0.07 ; 0.10)$ & $0.19(0.10 ; 0.29) *$ & $0.86(0.51 ; 1.21)^{*}$ \\
\hline & Age & $0.03(-0.04 ; 0.11)$ & $-0.01(-0.09 ; 0.08)$ & $0.07(-0.24 ; 0.39)$ \\
\hline
\end{tabular}

* Significant predictor at $0.05 .{ }^{*}$ Results represent regression coefficients $(\beta)$ and corresponding $95 \%$ confidence intervals $(\mathrm{CI})$. 
We found that boys have a higher life satisfaction $(\beta=0.42 ; 95 \%$ confidence interval, $95 \% \mathrm{CI}=-0.21$; $0.62)$ and they are less affected by depressive $(\beta=-0.90 ; 95 \% \mathrm{CI}=-1.14 ;-0.67)$ and psychosomatic symptoms $(\beta=-3.05 ; 95 \% \mathrm{CI}=-3.88 ;-2.21)$ than girls. The post estimation shows that the coefficients for boys, taking all three outcomes together, are statistically significant $(p<0.001)$. The results support the hypothesis that the three coefficients for male sex across the three equations are statistically significant. We also rejected the null hypothesis $(p<0.001)$ that the three coefficients for the variable male sex in the equation with life satisfaction, depression, and psychosomatic symptoms as the outcome measures are equal and do not differ from each other. This means that male sex is linked with various degrees to life satisfaction, depression, and psychosomatic symptoms. Those who did not know the educational attainment of their father $(\beta=1.83 ; 95 \% \mathrm{CI}=0.33 ; 3.32)$ or whose fathers had a vocational certificate $(\beta=1.04 ; 95 \% \mathrm{CI}=0.03 ; 2.05)$ had more psychosomatic symptoms than those whose fathers had a university or college certificate. The students who did not know the educational attainment of their mother $(\beta=-0.72 ; 95 \% \mathrm{CI}=-1.12 ;-0.32)$ were less satisfied with their lives, and those students whose mothers had lower educational attainment than secondary school had fewer psychosomatic symptoms (primary school: $\beta=-2.15 ; 95 \% \mathrm{CI}=-4.05 ;-0.25$ ) (vocational school: $\beta=-1.20 ; 95 \% \mathrm{CI}=-2.35 ;-0.06)$.

The lower subjective perception of family wealth had a negative effect on life satisfaction (not well-off: $\beta=-1.25 ; 95 \% \mathrm{CI}=-1.70 ;-0.80$ ), (average: $\beta=-0.48 ; 95 \% \mathrm{CI}=-0.66 ;-0.29$ ) and increased the development of depression $(\beta=0.80 ; 95 \% \mathrm{CI}=0.27 ; 1.32)$, while family affluence had no effect on these mental well-being indicators.

Students from primary schools perceived fewer psychosomatic symptoms than high school students $(\beta=-1.49 ; 95 \% \mathrm{CI}=-2.77 ;-0.21)$.

Those who had higher social support $(\beta=0.42 ; 95 \% \mathrm{CI}=0.34 ; 0.50)$ had better life satisfaction and had fewer depressive $(\beta=-0.75 ; 95 \% \mathrm{CI}=-0.84 ;-0.65)$ and psychosomatic symptoms $(\beta=-1.13$; $95 \% \mathrm{CI}=-1.47 ;-0.79)$.

Healthy food consumption was associated with higher life satisfaction $(\beta=0.20 ; 95 \% \mathrm{CI}=0.11$; 0.28 ), and those who consumed unhealthy foods were more likely to have psychosomatic ( $\beta=0.15$; $95 \% \mathrm{CI}=0.05 ; 0.24)$ and depressive symptoms $(\beta=0.84 ; 95 \% \mathrm{CI}=0.50 ; 1.19)$. Regular breakfast consumption and family meals were positively related to life satisfaction $(\beta=0.19 ; 95 \% \mathrm{CI}=0.11 ; 0.28)$, depression $(\beta=-0.46 ; 95 \% \mathrm{CI}=-0.56 ;-0.36)$, and psychosomatic symptoms $(\beta=-1.52 ; 95 \% \mathrm{CI}=-1.88$; $-1.17)$.

Regular physical activity had a positive effect on life satisfaction $(\beta=0.19 ; 95 \% \mathrm{CI}=0.10 ; 0.27)$ and depression $(\beta=-0.20 ; 95 \% \mathrm{CI}=-0.30 ;-0.10)$, while higher entertainment screen time was related to lower life satisfaction $(\beta=-0.15 ; 95 \% \mathrm{CI}=-0.24 ;-0.06)$ and a higher risk of depression $(\beta=0.17$; $95 \% \mathrm{CI}=0.07 ; 0.27)$. Computer usage that was not for playing games increased the risk of depression $(\beta=0.19 ; 95 \% \mathrm{CI}=0.10 ; 0.29)$ and psychosomatic symptoms $(\beta=0.86 ; 95 \% \mathrm{CI}=0.51 ; 1.21)$.

\section{Discussion}

The mental well-being of adolescents was characterized based on three domains: life satisfaction, the presence of psychosomatic symptoms, and depression. Regarding our results, each well-being domain for boys-similar to the international and national survey $[7,8]$ - was favorable compared to those for girls, but there was no association with age and place of living. The sensitivity analysis also shows that these sex differences simultaneously exist, independent of other factors, across all the studied well-being variables. The differences among adolescents in psychosomatic symptoms, depression, and life satisfaction significantly varied across boys and girls; the effect of gender on well-being domains exists to various degrees. Based on the results of previous studies these differences may be explained partly by the hormonal, physical and psychological changes caused by puberty in girls, which are not necessarily consistent with the ideal self-image or can lead to sexualization. Another cause can be if there is a big contrast between familial, peer and mass media values. Furthermore, the social environment will change in that period, the parents probably will be stricter with girls, and also the 
school performance has greater importance for them, which can lead to increased stress. From a sociological point of view, society usually overvalues maleness, which can enhance the development of role conflicts among young women [25-27]. From the socioeconomic determinants, there was no clear relationship either with parental educational attainment or with the material assets of the family; however, lower subjective family wealth was associated with lower life satisfaction and depressive mood.

These results are in line with a previous meta-analysis suggesting that mental well-being is linked to subjective socioeconomic status (SES) and that the effect is independent of objective SES. This can perhaps be explained by the hypothesis that subjective SES reflects the relative status while objective SES is the absolute social position of a person, and the perception of socioeconomic rank can influence mental health outcomes through psychological processes [12].

Life satisfaction was positively related to healthy eating, social support, and physical activity. Unhealthy eating, sedentary lifestyle, and lower social support were associated with higher depression scores. Higher social support and eating together with parents decrease psychosomatic symptoms, while unhealthy eating and spending more time before the computer increase them.

Our results do not differ from those of previous studies where the effect of similar factors (but not all of them together) was investigated. Thus, the same relationships have been found concerning the connection between mental health and healthy eating $[18,28,29]$. The reason for this association could be the appropriate intake of micronutrients and vitamins which are necessary for proper mental function, and probably because negative mood can lead to the frequent consumption of unhealthier foods as a coping mechanism (to increase the serotonin level). The positive effect of physical activity on mental health has also been proven [28,30,31]; this could be because of the physiological effects of exercise, because of an indirect effect due to increased self-esteem, or be connected with social support. Furthermore, the time spent engaging in screen-based activities has been connected to mental health problems by Brindova et al. [32], Hoare et al. [33], and Iannotti et al. [19]. This may be due to the decreased opportunity to be active, but the effect of the content of videos and games could also influence well-being, or it could be that those who already have mental health problems will choose these activities as compensation. The opportunity to communicate with parents along with support from family and peers are also established as protective factors for mental well-being $[15,34]$ because these can help to improve social skills, raise self-esteem, and enhance one's sense of security and belonging, which can strengthen one's ability to cope with stress.

\section{Strengths and Limitations}

The uncertainty of the answers can be high for some variables (e.g., educational attainment of the parents), as the younger children did not all know this information. Because our questionnaire was the same as that used in the Hungarian HBSC survey, which was developed following international protocol, the uncertainty for these items is expected to be no higher than in other countries. Imputation was used to minimize the bias that may arise from missing data. Due to the cross-sectional design, clear conclusions cannot be drawn about the causal effect, but this study does provide a foundation for elucidating the relationship between the factors. Among the strengths of our study, we can mention the relatively large sample size and the fact that the determinants of mental well-being were investigated from a complex point of view using advanced statistical methods.

\section{Conclusions}

In this study, we aimed to contribute to the literature concerning adolescents' well-being and effective intervention planning by investigating (1) whether socioeconomic status, social support, and health behavior are connected with mental well-being; (2) the potential gender differences between mental well-being domains independent of socioeconomic factors; (3) and, if these differences exist, whether this association differed according to gender. 
Both social support and healthy lifestyle are important protective factors against mental health problems among adolescents, so interventions should focus on these factors regardless of the socioeconomic status of the participants, with special attention given to girls. Taking into consideration previous intervention studies [35,36], it can be stated that the development of effective interventions is a challenge; therefore, any kind of study which is able to add one piece to this puzzle can be meaningful.

The importance of our research can be highlighted by the fact that The United Nations Children's Fund (UNICEF) and the WHO advocate putting child and adolescent mental health higher up on the global health agenda, taking into consideration its magnitude (high rates of self-harm, suicide, and mental health problems). Studies similar to ours can help us to understand the leading factors in mental health and can lead to providing better service for adolescents. One example of this could be a school-based mental health screening program [37].

Author Contributions: Conceptualization, G.N.-P. and É.B.; methodology, G.N.-P., F.V., and É.B.; formal analysis, F.V.; investigation, G.N.-P. and É.B.; writing—original draft preparation, G.N.-P. and F.V.; writing—review and editing, É.B.; visualization, F.V.; supervision, É.B.; funding acquisition, É.B. All authors have read and agreed to the published version of the manuscript.

Funding: This work was supported by the "3rd Mission-Sport and Science for Society in Eastern Hungary", titled the TÁMOP-4.1.2.E-15/1/KONV-2015-0001 project, and data evaluation was carried out in the framework of the GINOP-2.3.2-15-2016-00005 project, which is co-financed by the European Union under the European Regional Development Fund. The funders have had no influence on the study design, data collection and analysis, interpretation of the results, writing of the manuscript, or in the decision to submit it for publication.

Acknowledgments: The authors would like to thank the following people and institutions for participation in the study: Károly Fekete, Bishop of Transtibiscan Reformed Church District on behalf of the Reformed Church, András Vántusné on behalf of the Klebelsberg Institution Maintenance Centre, Debrecen Centre of Vocational Training, and the teachers and pupils involved in the Debrecen schools. We would like to give thanks to Ágnes Németh, the principal investigator of the Hungarian Health Behavior in School-aged Children (HBSC) study, for the methodological help, and to Tibor Gáll for ensuring the conditions of the online data collection. We are also grateful for the participants of the fieldwork—namely, Barbara Bagin, Adrienn Deme, Márta Fúzi, Szilvia Gergely, Enikő Kerékgyártó, and Renáta Turi.

Conflicts of Interest: The authors declare no conflict of interest. The funders had no role in the design of the study; in the collection, analysis, or interpretation of data; in the writing of the manuscript; or in the decision to publish the results. 


\section{Appendix A}

Table A1. Characteristics of the respondents after the multiple imputation of missing values.

\begin{tabular}{|c|c|c|c|c|c|}
\hline & & \multicolumn{2}{|c|}{ Before Imputation } & \multicolumn{2}{|c|}{ After Imputation } \\
\hline & & $\mathbf{N}(\%)$ & Mean $( \pm$ SD) & $\mathbf{N}(\%)$ & Mean $( \pm \mathrm{SD})$ \\
\hline \multicolumn{2}{|l|}{ Age (missing: $0.91 \%)$} & & $15.28(1.70)$ & & $15.28(1.70)$ \\
\hline \multirow{2}{*}{ Gender of students (missing: $0 \%$ ) } & Male & $997(60.76 \%)$ & & $997(60.76 \%)$ & \\
\hline & Female & $644(39.24 \%)$ & & $644(39.24 \%)$ & \\
\hline \multirow{5}{*}{ Educational attainment of father (missing: $5.12 \%$ ) } & Not known & $181(11.62 \%)$ & & $189(11.52 \%)$ & \\
\hline & Primary school or less & $60(3.85 \%)$ & & $75(4.57 \%)$ & \\
\hline & Vocational school & $434(27.87 \%)$ & & $459(27.97 \%)$ & \\
\hline & Secondary school/high school & $375(24.08 \%)$ & & $397(24.19 \%)$ & \\
\hline & University/college & $507(32.56 \%)$ & & $521(31.75 \%)$ & \\
\hline \multirow{5}{*}{ Educational attainment of mother (missing: $5.79 \%$ ) } & Not known & $131(8.47 \%)$ & & $132(8.04 \%)$ & \\
\hline & Primary school or less & $60(3.88 \%)$ & & $74(4.51 \%)$ & \\
\hline & Vocational school & $214(13.84 \%)$ & & $244(14.87 \%)$ & \\
\hline & Secondary school/high school & $515(33.31 \%)$ & & $544(33.15 \%)$ & \\
\hline & University/college & $626(40.49 \%)$ & & $647(39.43 \%)$ & \\
\hline \multirow{3}{*}{ Family affluence (missing: $1.77 \%$ ) } & Low & $645(43.58 \%)$ & & $715(43.57 \%)$ & \\
\hline & Medium & $656(44.32 \%)$ & & $725(44.18 \%)$ & \\
\hline & High & $179(12.09 \%)$ & & $201(12.25 \%)$ & \\
\hline \multirow{3}{*}{ Subjective perception of family wealth (missing: $1.77 \%$ ) } & Not well-off & $63(3.91 \%)$ & & $63(3.84 \%)$ & \\
\hline & Average & $918(56.95 \%)$ & & $933(56.86 \%)$ & \\
\hline & Well-off & $631(39.14 \%)$ & & $645(39.31 \%)$ & \\
\hline
\end{tabular}


Table A1. Cont.

\begin{tabular}{|c|c|c|c|c|c|}
\hline & & \multicolumn{2}{|c|}{ Before Imputation } & \multicolumn{2}{|c|}{ After Imputation } \\
\hline & & $\mathbf{N}(\%)$ & Mean $( \pm$ SD) & $\mathbf{N}(\%)$ & Mean $( \pm$ SD) \\
\hline \multirow{2}{*}{ Residence (missing: $0.24 \%$ ) } & Debrecen & $1012(61.82 \%)$ & & $1015(61.85 \%)$ & \\
\hline & Other surrounding settlements & $625(38.18 \%)$ & & $626(38.15 \%)$ & \\
\hline \multirow{4}{*}{ Type of school (missing: $0.61 \%$ ) } & Primary school & $358(21.95 \%)$ & & $358(21.82 \%)$ & \\
\hline & Vocational school & $62(3.80 \%)$ & & $66(4.02 \%)$ & \\
\hline & Secondary school & $516(31.64 \%)$ & & $518(31.57 \%)$ & \\
\hline & High school & $695(42.61 \%)$ & & $699(42.60 \%)$ & \\
\hline \multicolumn{2}{|c|}{ Life satisfaction (missing: $6.46 \%$ ) } & & $7.42(1.94)$ & & $7.39(1.92)$ \\
\hline \multicolumn{2}{|c|}{ Depression scale (missing: $13.16 \%$ ) } & & $2.12(2.44)$ & & $2.11(2.40)$ \\
\hline \multicolumn{2}{|c|}{ Psychosomatic symptoms (missing: 8.78\%) } & & $21.17(7.77)$ & & $21.17(7.57)$ \\
\hline
\end{tabular}

$\mathrm{N}$ : number of cases. SD: standard deviation.

Table A2. Factor structure of the variables measuring social support and health behavior.

\begin{tabular}{|c|c|c|c|c|c|c|c|c|c|}
\hline & \multirow[b]{2}{*}{$\begin{array}{c}\text { Median } \\
\text { (Interquartile } \\
\text { Range) }\end{array}$} & \multicolumn{7}{|c|}{ Factors } & \multirow[b]{2}{*}{ Communalities } \\
\hline & & $\begin{array}{l}\text { Unhealthy } \\
\text { Food } \\
\text { Consumption }\end{array}$ & Screen Time & $\begin{array}{l}\text { Physical } \\
\text { Activity }\end{array}$ & $\begin{array}{c}\text { Social } \\
\text { Support }\end{array}$ & $\begin{array}{l}\text { Using the } \\
\text { Computer } \\
\text { Not for } \\
\text { Playing }\end{array}$ & $\begin{array}{c}\text { Breakfast } \\
\text { Consumption } \\
\text { and Family } \\
\text { Meals }\end{array}$ & $\begin{array}{l}\text { Healthy Food } \\
\text { Consumption }\end{array}$ & \\
\hline Frequency of salty snacks consumption & $3(2)$ & 0.812 & 0.122 & -0.024 & 0.012 & 0.034 & 0.113 & 0.005 & 0.688 \\
\hline $\begin{array}{l}\text { Frequency of sugar-containing soft } \\
\text { drinks consumption }\end{array}$ & $3(3)$ & 0.778 & 0.137 & -0.063 & 0.081 & 0.037 & -0.070 & -0.092 & 0.649 \\
\hline Frequency of fast-foods consumption & $2(1)$ & 0.731 & 0.124 & 0.092 & -0.008 & 0.081 & 0.007 & 0.016 & 0.565 \\
\hline Frequency of sweets consumption & $4(2)$ & 0.685 & -0.024 & -0.065 & -0.013 & -0.040 & 0.154 & 0.129 & 0.516 \\
\hline Frequency of energy drinks consumption & $1(1)$ & 0.558 & 0.144 & 0.058 & -0.080 & 0.190 & -0.206 & -0.048 & 0.422 \\
\hline Playing on the computer on weekdays & $3(3)$ & 0.167 & 0.816 & 0.025 & -0.033 & -0.020 & 0.051 & -0.061 & 0.703 \\
\hline Playing on the computer on weekends & $4(4)$ & 0.113 & 0.811 & -0.005 & -0.025 & -0.042 & 0.080 & -0.129 & 0.696 \\
\hline
\end{tabular}


Table A2. Cont.

\begin{tabular}{|c|c|c|c|c|c|c|c|c|c|}
\hline & \multirow[b]{2}{*}{$\begin{array}{c}\text { Median } \\
\text { (Interquartile } \\
\text { Range) }\end{array}$} & \multicolumn{7}{|c|}{ Factors } & \multirow[b]{2}{*}{ Communalities } \\
\hline & & $\begin{array}{l}\text { Unhealthy } \\
\text { Food } \\
\text { Consumption }\end{array}$ & Screen Time & $\begin{array}{l}\text { Physical } \\
\text { Activity }\end{array}$ & $\begin{array}{l}\text { Social } \\
\text { Support }\end{array}$ & $\begin{array}{l}\text { Using the } \\
\text { Computer } \\
\text { Not for } \\
\text { Playing }\end{array}$ & $\begin{array}{c}\text { Breakfast } \\
\text { Consumption } \\
\text { and Family } \\
\text { Meals }\end{array}$ & $\begin{array}{l}\text { Healthy Food } \\
\text { Consumption }\end{array}$ & \\
\hline Watching TV and videos on weekdays & $3(2)$ & 0.129 & 0.676 & -0.088 & -0.016 & 0.290 & -0.107 & 0.074 & 0.583 \\
\hline Watching TV and videos on weekends & $5(3)$ & 0.081 & 0.628 & -0.118 & -0.046 & 0.319 & -0.183 & 0.044 & 0.555 \\
\hline Frequency of vigorous physical activity & $6(2)$ & 0.023 & -0.056 & 0.861 & 0.070 & -0.031 & 0.025 & 0.116 & 0.765 \\
\hline Weekly hours of vigorous physical activity & $4(3)$ & -0.050 & -0.059 & 0.839 & 0.069 & -0.024 & 0.005 & 0.040 & 0.718 \\
\hline Moderate-to-vigorous physical activity & $5(3)$ & 0.023 & -0.009 & 0.791 & -0.004 & 0.028 & 0.139 & 0.107 & 0.657 \\
\hline Perceived social support from family & $26(5)$ & -0.003 & 0.006 & 0.010 & 0.834 & -0.049 & 0.222 & 0.034 & 0.748 \\
\hline Quality of family communication & $17(3)$ & -0.050 & 0.040 & 0.051 & 0.806 & -0.080 & 0.200 & 0.069 & 0.708 \\
\hline $\begin{array}{l}\text { Perceived social support from friends } \\
\text { (peer support) }\end{array}$ & $26(5)$ & 0.050 & -0.149 & 0.081 & 0.665 & 0.139 & -0.153 & 0.079 & 0.522 \\
\hline $\begin{array}{l}\text { Using the computer not for playing } \\
\text { on weekdays }\end{array}$ & $4(3)$ & 0.133 & 0.159 & -0.012 & -0.001 & 0.881 & -0.064 & -0.019 & 0.824 \\
\hline $\begin{array}{l}\text { Using the computer not for playing } \\
\text { on weekends }\end{array}$ & $5(4)$ & 0.069 & 0.122 & 0.000 & 0.016 & 0.894 & -0.056 & -0.013 & 0.823 \\
\hline Breakfast with the parents & $3(2)$ & 0.088 & -0.035 & 0.039 & 0.200 & -0.030 & 0.794 & 0.114 & 0.695 \\
\hline Breakfast consumption on weekdays & $5(5)$ & -0.036 & -0.024 & 0.117 & -0.120 & -0.085 & 0.685 & -0.025 & 0.508 \\
\hline Evening meal with the parents & $4(3)$ & 0.020 & -0.013 & 0.009 & 0.326 & -0.026 & 0.658 & 0.218 & 0.588 \\
\hline Frequency of vegetables consumption & $4(2)$ & -0.038 & -0.020 & 0.098 & 0.087 & 0.003 & 0.092 & 0.887 & 0.814 \\
\hline Frequency of fruit consumption & $4(2)$ & 0.060 & -0.068 & 0.173 & 0.093 & -0.027 & 0.129 & 0.858 & 0.799 \\
\hline Eigenvalue & & 3.765 & 3.048 & 1.967 & 1.808 & 1.548 & 1.330 & 1.080 & \\
\hline Explained variance (\%) & & 17.114 & 13.856 & 8.941 & 8.218 & 7.036 & 6.046 & 4.909 & \\
\hline
\end{tabular}
(KMO): 0.716; Bartlett's Test of Sphericity: $p<0.001$; total variance explained: $66.12 \%$.

The numbers represent the standardized factor loadings for the 7 -factor model. Values of factor loading higher than 0.5 are emphasized in bold. 


\section{References}

1. World Health Organization. Adolescent Mental Health: Mapping Actions of Nongovernmental Organizations and Other International Development Organizations. Available online: https://apps.who.int/iris/bitstream/ handle/10665/44875/9789241503648_eng.pdf;jsessionid=2E6F176D74F28C01798AA5F8F7468A01? sequence $=1$ (accessed on 8 September 2020).

2. Belfer, M.L. Child and Adolescent Mental Disorders: The Magnitude of the Problem across the Globe. J. Child Psychol. Psychiatry 2008, 49, 226-236. [CrossRef]

3. Patel, V.; Flisher, A.J.; Hetrick, S.; McGorry, P. Mental Health of Young People: A Global Public-Health Challenge. Lancet 2007, 369, 1302-1313. [CrossRef]

4. World Health Organization. Investing in Children: The European Child and Adolescent Health Strategy 2015-2020 Regional Committee for Europe 64th Session; WHO Regional Office for Europe: Copenhagen, Denmark, 2014; Available online: https://www.euro.who.int/_data/assets/pdf_file/0010/253729/64wd12e_ InvestCAHstrategy_140440.pdf?ua= (accessed on 8 September 2020).

5. Whiteford, H.A.; Degenhardt, L.; Rehm, J.; Baxter, A.J.; Ferrari, A.J.; Erskine, H.E.; Charlson, F.J.; Norman, R.E.; Flaxman, A.D.; Johns, N.; et al. Global Burden of Disease Attributable to Mental and Substance Use Disorders: Findings from the Global Burden of Disease Study 2010. Lancet 2013, 382, 1575-1586. [CrossRef]

6. HBSC International Coordinating Centre Child \& Adolescent Health Research Unit. Health Behaviour in School-Aged Children (HBSC) 2014: Terms of Reference. Available online: http://www.hbsc.org/about/ HBSCToR.pdf (accessed on 8 September 2020).

7. Inchley, J.; Currie, D.; Young, T.; Samdal, O.; Torsheim, T.; Augustson, L.; Mathison, F.; Aleman-Diaz, A.; Molcho, M.; Weber, M.B. (Eds.) Growing up Unequal: Gender and Socioeconomic Differences in Young People's Health and Well-Being. Health Behaviour in School-Aged Children (HBSC) Study: International Report from the 2013/2014 Survey; World Health Organization Regional Office for Europe: Copenhagen, Denmark, 2016.

8. Németh, Á.; Költő, A. Health Behaviour in School-Aged Children (HBSC): A WHO-Collaborative Cross-National Study. National Report 2014; National Institute for Health Promotion: Budapest, Hungary, 2016.

9. Patton, G.C.; Sawyer, S.M.; Santelli, J.S.; Ross, D.A.; Afifi, R.; Allen, N.B.; Arora, M.; Azzopardi, P.; Baldwin, W.; Bonell, C.; et al. Our Future: A Lancet Commission on Adolescent Health and Wellbeing. Lancet 2016, 387, 2423-2478. [CrossRef]

10. World Health Organization. Mental Health: New Understanding, New Hope; The World Health Report; 2001. Available online: https://www.who.int/whr/2001/en/whr01_en.pdf?ua=1 (accessed on 8 September 2020).

11. Klanšček, H.J.; Žiberna, J.; Korošec, A.; Zurc, J.; Albreht, T. Mental Health Inequalities in Slovenian 15-Year-Old Adolescents Explained by Personal Social Position and Family Socioeconomic Status. Int. J. Equity Health 2014, 13, 26. [CrossRef]

12. Quon, E.C.; McGrath, J.J. Subjective Socioeconomic Status and Adolescent Health: A Meta-Analysis. Health Psychol. Off. J. Div. Health Psychol. Am. Psychol. Assoc. 2014. [CrossRef]

13. Sweeting, H.; Hunt, K. Adolescent Socio-Economic and School-Based Social Status, Health and Well-Being. Soc. Sci. Med. 2014, 121, 39-47. [CrossRef]

14. Viner, R.M.; Ozer, E.M.; Denny, S.; Marmot, M.; Resnick, M.; Fatusi, A.; Currie, C. Adolescence and the Social Determinants of Health. Lancet 2012, 379, 1641-1652. [CrossRef]

15. Currie, C.; Zanotti, C.; Morgan, A.; Currie, D.; de Looze, M.H.; Roberts, C.; Samdal, O.; Otto, R.F.; Smith, V.B. Social Determinants of Health and Well-Being among Young People. In Health Behaviour in School-Aged Children (HBSC) Study: International Report from the 2009/2010 Survey; World Health Organization Regional Office for Europe: Copenhagen, Denmark, 2012.

16. World Health Organization. Social Cohesion for Mental Well-Being among Adolescents. 2007. Available online: http://www.euro.who.int/_data/assets/pdf_file/0005/84623/E91921.pdf (accessed on 8 September 2020).

17. World Health Organization. Risks to Mental Health: An Overview of Vulnerabilities and Risk Factors. 2012. Available online: http://www.who.int/mental_health/mhgap/risks_to_mental_health_EN_27_08_12.pdf (accessed on 8 September 2020).

18. Brookie, K.L.; Best, G.I.; Conner, T.S. Intake of Raw Fruits and Vegetables Is Associated With Better Mental Health Than Intake of Processed Fruits and Vegetables. Front Psychol 2018, 9, 487. [CrossRef] 
19. Iannotti, R.J.; Janssen, I.; Haug, E.; Kololo, H.; Annaheim, B.; Borraccino, A.; the HBSC Physical Activity Focus Group. Interrelationships of Adolescent Physical Activity, Screen-Based Sedentary Behaviour, and Social and Psychological Health. Int. J. Public Health 2009, 54, 191-198. [CrossRef]

20. Vancampfort, D.; Stubbs, B.; Firth, J.; Van Damme, T.; Koyanagi, A. Sedentary Behavior and Depressive Symptoms among 67,077 Adolescents Aged 12-15 Years from 30 Low- and Middle-Income Countries. Int. J. Behav. Nutr. Phys. Act. 2018, 15, 73. [CrossRef]

21. Bíró, É.; Dezső, D.; Sándor, J.; Ádány, R. Inequalities in Hungarian Adolescents' Health, Health Behaviour and Well-Being, Based upon the Results of a Cross-Sectional Survey at Settlement Level, Using the Health Behaviour in School-Aged Children Questionnaire. Child. Youth Serv. Rev. 2018, 90, 15-20. [CrossRef]

22. Currie, C.; Inchley, J.; Molcho, M.; Lenzi, M.; Veselska, Z.; Wild, F. Health Behaviour in School-Aged Children (HBSC) Study Protocol: Background, Methodology and Mandatory Items for the 2013/14 Survey; CAHRU: Andrews, UK, 2014.

23. Kovacs, M. The Children's Depression, Inventory (CDI). Psychopharmacol. Bull. 1985, 21, 995-998.

24. StataCorp. Stata Statistical Software: Release 12; StataCorp LP: College Station, TX, USA, 2011.

25. Cavallo, F.; Zambon, A.; Borraccino, A.; Raven-Sieberer, U.; Torsheim, T.; Lemma, P.; the HBSC Positive Health Group. Girls Growing through Adolescence Have a Higher Risk of Poor Health. Qual. Life Res. 2006, 15, 1577-1585. [CrossRef]

26. Silva, S.A.; Silva, S.U.; Ronca, D.B.; Gonçalves, V.S.S.; Dutra, E.S.; Carvalho, K.M.B. Common Mental Disorders Prevalence in Adolescents: A Systematic Review and Meta-Analyses. PLoS ONE 2020, 15, e0232007. [CrossRef]

27. Landstedt, E.; Asplund, K.; Gillander Gådin, K. Understanding Adolescent Mental Health: The Influence of Social Processes, Doing Gender and Gendered Power Relations. Sociol. Health Illn. 2009, 31, 962-978. [CrossRef]

28. Grant, N.; Wardle, J.; Steptoe, A. The Relationship Between Life Satisfaction and Health Behavior: A Cross-Cultural Analysis of Young Adults. Int. J. Behav. Med. 2009, 16, 259-268. [CrossRef]

29. Hong, S.A.; Peltzer, K. Dietary Behaviour, Psychological Well-Being and Mental Distress among Adolescents in Korea. Child Adolesc. Psychiatry Ment. Health 2017, 11, 56. [CrossRef]

30. Bell, S.L.; Audrey, S.; Gunnell, D.; Cooper, A.; Campbell, R. The Relationship between Physical Activity, Mental Wellbeing and Symptoms of Mental Health Disorder in Adolescents: A Cohort Study. Int. J. Behav. Nutr. Phys. Act. 2019, 16, 138. [CrossRef]

31. Ho, F.K.W.; Louie, L.H.T.; Chow, C.B.; Wong, W.H.S.; Ip, P. Physical Activity Improves Mental Health through Resilience in Hong Kong Chinese Adolescents. BMC Pediatr. 2015, 15, 48. [CrossRef]

32. Brindova, D.; Veselska, Z.D.; Klein, D.; Hamrik, Z.; Sigmundova, D.; van Dijk, J.P.; Reijneveld, S.A.; Geckova, A.M. Is the Association between Screen-Based Behaviour and Health Complaints among Adolescents Moderated by Physical Activity? Int. J. Public Health 2015, 60, 139-145. [CrossRef]

33. Hoare, E.; Milton, K.; Foster, C.; Allender, S. The Associations between Sedentary Behaviour and Mental Health among Adolescents: A Systematic Review. Int. J. Behav. Nutr. Phys. Act. 2016, 13, 108. [CrossRef]

34. Roche, K.M.; Bingenheimer, J.B.; Ghazarian, S.R. The Dynamic Interdependence between Family Support and Depressive Symptoms among Adolescents in Ghana. Int. J. Public Health 2016, 61, 487-494. [CrossRef]

35. Dray, J.; Bowman, J.; Campbell, E.; Freund, M.; Hodder, R.; Wolfenden, L.; Richards, J.; Leane, C.; Green, S.; Lecathelinais, C.; et al. Effectiveness of a Pragmatic School-Based Universal Intervention Targeting Student Resilience Protective Factors in Reducing Mental Health Problems in Adolescents. J. Adolesc. 2017, 57, 74-89. [CrossRef] 
36. Jenkins, E.K.; Bungay, V.; Patterson, A.; Saewyc, E.M.; Johnson, J.L. Assessing the Impacts and Outcomes of Youth Driven Mental Health Promotion: A Mixed-Methods Assessment of the Social Networking Action for Resilience Study. J. Adolesc. 2018, 67, 1-11. [CrossRef]

37. Husky, M.M.; Kaplan, A.; McGuire, L.; Flynn, L.; Chrostowski, C.; Olfson, M. Identifying Adolescents at Risk through Voluntary School-Based Mental Health Screening. J. Adolesc. 2011, 34, 505-511. [CrossRef]

Publisher's Note: MDPI stays neutral with regard to jurisdictional claims in published maps and institutional affiliations.

(C) 2020 by the authors. Licensee MDPI, Basel, Switzerland. This article is an open access article distributed under the terms and conditions of the Creative Commons Attribution (CC BY) license (http://creativecommons.org/licenses/by/4.0/). 